\title{
O interesse público e a liberdade de imprensa como fundamentos da comunicação jornalística democrática
}

PUBLIC INTEREST AND FREEDOM OF THE PRESS AS THE FOUNDATION OF THE DEMOCRATIC JOURNALISTIC COMMUNICATION

L Maria Elisabete Antonioli

Doutora em Ciências da Comunicação pela Escola de Comunicações e Artes da Universidade de São Paulo (ECA/USP). Coordenadora e professora do Mestrado Profissional de Produção Jornalística e Mercado da Escola Superior de Propaganda e Marketing (ESPM).

E-mail: mantonioli@espm.br

\section{Cassio Cavalcante Andrade}

Mestre em Direito pela Pontifícia Universidade Católica de São Paulo (PUC-SP). Professor de Ética no Jornalismo e Direitos Humanos do curso de Jornalismo da Escola Superior de Propaganda e Marketing (ESPM). Advogado da União.

E-mail: cassio.andrade@espm.br

Recebido em 31 de janeiro de 2017. Aprovado em 19 de abril de 2017.

\section{Resumo}

Orientado por uma pesquisa bibliográfica, este trabalho tem como objetivo discutir o interesse público e a liberdade de imprensa como condições precípuas para o desenvolvimento da sociedade e afirmação da democracia. O jornalismo é uma profissão social e o interesse público, o norte do jornalista. Entretanto, embaraços de ordens diversas podem ser ameaças para o jornalismo.
Nessa perspectiva, estas questões são discutidas à luz de autores que tratam da profissão do jornalista e de autores das ciências jurídicas que veem o jornalismo e o interesse público como valores inquestionáveis no processo de evolução social.

Palavras-chave: Interesse público. Liberdade de imprensa. Democracia.

18

Comunicação \& Inovação, PPGCOM/USCS 


\section{Abstract}

Based on a bibliographical research, this article aims to discuss public interest and freedom of the press as preconditions for the development of society and affirmation of democracy. Journalism is a social profession, and public interest guides the journalist. However, several restrictions may threat journalism. In such perspective, these issues are analyzed according to authors that address the profession of the journalist and authors who study the legal sciences and consider journalism and public interest as unquestionable values in the process of social evolution.

Keywords: Public interest. Freedom of the press. Democracy.

\section{Introdução}

O interesse público, objeto do discurso jornalístico e orientador da sua práxis, tem sido, ao longo do tempo, motivo de reflexões por parte de diversos pensadores que veem o jornalismo como uma necessidade social e cuja prática profissional tem como premissa um trabalho a serviço dos cidadãos. Portanto, a própria profissão é vista a partir do interesse público, o que levou o jornalismo a se legitimar sob essa perspectiva.

Interesse público e liberdade de imprensa têm, nesse particular, estreita e necessária relação, pois só é possível que a ação jornalística ocorra tendo como norte o interesse e os direitos dos indivíduos com vistas a um regime democrático, que pressupõe livre apuração, investigação e divulgação das informações. É o jornalismo livre em seu sentido lato, tanto no que diz respeito às esferas governamentais quanto à iniciativa privada, e, nessa conjuntura, será possível seu pleno exercício tal qual sua constituição.

O jornalismo socialmente útil somente pode ser exercido adequadamente em uma democracia, e esta, por sua vez, demandará sempre de um jornalismo independente. Fora dos quadrantes democráticos, o jornalismo não passa da sombra de si mesmo, constituindo-se, quase sempre, na prática divulgadora de regimes obscuros, sem qualquer comprometimento com a verdade, com as liberdades públicas e com os direitos humanos. Servindo a governos escancaradamente totalitários ou pseudodemocráticos, como mero reprodutor de fatos e relator parcial e irresponsável da história opressora, a imprensa torna-se mero legitimador da versão oficial do Estado. Por outro lado, quando diante de governos não democráticos, insurge-se, denunciando as mais diversas violações aos direitos do cidadão; realiza relevante trabalho, funcionando como verdadeira missão humanitária 
libertadora, conquanto, por óbvio, o desvelamento da verdade reste comprometido pela inacessibilidade própria dos regimes, excepcionais ou não, de força. Daí é que se sustenta que o ambiente democrático é o meio de cultura adequado para o exercício do jornalismo.

Por isso é que se crava, sem receio de erro, que imprensa boa é imprensa livre, absolutamente livre, sem amarras. Mesmo que se trate de um ideal, de uma projeção quase utópica, de um objetivo a ser perseguido e concretizado, justamente porque a realidade dos poderes político e econômico sempre impõe algum nível de abuso, com consequentes opressão e exploração, tanto melhor será a imprensa quanto mais imune for a esses abusos e influências. Portanto, nessas condições limitadas, a excelência residirá na capacidade que os veículos e profissionais do jornalismo terão de se desvincular dos interesses políticos e econômicos parciais e de permanecer longe deles por mais tempo.

Eis a tão eminente "liberdade de imprensa" que se traduz também no título do artigo do jornalista Líbero Badaró, publicado em seu jornal Observador Constitucional, em 1829, que diz:

O direito de segurança individual, precioso para cada cidadão, é debaixo da imediata dependência da liberdade de imprensa, e ninguém certamente atrever-se-á negá-lo, se quiser se lembrar a facilidade com que se pode secretamente violar esse direito; e como seja difícil de sabê-lo, e, portanto, reparar esta violação (apud FERREIRA, 2011).

Ainda nessa perspectiva, Traquina (2008) chama atenção para a teoria democrática que reconhece uma primeira competência específica do jornalista: o fornecimento de informação à sociedade. O pesquisador diz que, na teoria democrática, existe uma relação considerada simbiótica entre jornalismo e democracia, afirmando ainda que "o jornalismo é, por excelência, uma atividade ligada às relações humanas [...]” (TRAQUINA, 2004, p. 115).

E deve ser ainda mais largo o espectro de compreensão dessa liberdade de imprensa, como pontuou o ministro Ayres Britto, no julgamento da referencial Arguição de Descumprimento de Preceito Fundamental (ADPF) n 130 (BRASIL, 2009, p. 40), ao encerrar que "assim visualizada como verdadeira irmã siamesa da democracia, a imprensa passa a desfrutar de uma liberdade de atuação ainda maior que a liberdade de pensamento e de expressão dos indivíduos em si mesmos considerados".

Neste trabalho, a instituição do interesse público e a liberdade de imprensa, vistas como precípuas referências para o jornalismo, são tratadas tanto por teóricos que se dedicam à discussão da profissão do jornalista, quanto por parte daqueles que se dedicam às ciências jurídicas e que trabalham com o direito da sociedade à informação. No caso, estudiosos do jornalismo e do direito, cada qual a partir de um modo peculiar de abordagem 
cognitiva, desenvolvem suas reflexões observando as mesmas premissas basilares que, a um só tempo, constituem o fazer jornalístico, mas também objeto de interesse da problemática jurídica. Nesse sentido, é interessante a lembrança de que o direito à informação é garantido pela Declaração Universal dos Direitos Humanos (ONU, 1948), em seu artigo XIX, que informa:

Todo ser humano tem direito à liberdade de opinião e expressão; este direito inclui a liberdade de, sem interferência, ter opiniões e de procurar, receber e transmitir informações e ideias por quaisquer meios e independentemente de fronteiras.

Já a Constituição Federal de 1988 (BRASIL, 1988), representante das instituições democráticas no Brasil e garantidora do pleno exercício da cidadania, dedica-se ao assunto, entre outras passagens, em seu art. $n^{\circ} 5$, ao prever:

IV - é livre a manifestação do pensamento, sendo vedado o anonimato;

$\mathrm{V}$ - é assegurado o direito de resposta, proporcional ao agravo, além da indenização por dano material, moral ou à imagem;

IX - é livre a expressão da atividade intelectual, artística, científica e de comunicação, independentemente de censura ou licença;

XIV - é assegurado a todos o acesso à informação e resguardado o sigilo da fonte, quando necessário ao exercício profissional.

Com relação específica ao jornalismo, o próprio Código de Ética dos Jornalistas Brasileiros, publicado pela Federação Nacional dos Jornalistas (2007), no art. $2^{\circ}$, dispõe:

Como o acesso à informação de relevante interesse público é um direito fundamental, os jornalistas não podem admitir que ele seja impedido por nenhum tipo de interesse, razão por que: I - a divulgação da informação precisa e correta é dever dos meios de comunicação e deve ser cumprida independentemente de sua natureza jurídica - se pública, estatal ou privada - e da linha política de seus proprietários e/ou diretores;

II - a produção e a divulgação da informação devem se pautar pela veracidade dos fatos e ter por finalidade o interesse público;

III - a liberdade de imprensa, direito e pressuposto do exercício do jornalismo, implica compromisso com a responsabilidade social inerente à profissão;

IV - a prestação de informações pelas organizações públicas e privadas, incluindo as não governamentais, é uma obrigação social; 
V - a obstrução direta ou indireta à livre divulgação da informação, a aplicação de censura e a indução à autocensura são delitos contra a sociedade, devendo ser denunciadas à comissão de ética competente, garantido o sigilo do denunciante.

Ao longo desses anos, a atuação dos profissionais da imprensa, por sua vez tem contribuído para que a sociedade receba informações profissionalmente qualificadas, que atendam ao interesse público e contribuam significativamente com a cidadania e o desenvolvimento social.

\section{O interesse público no jornalismo}

Principalmente em países como o Brasil, de democracia recente e em consolidação, a participação do jornalismo na vida das pessoas exerce caráter fundamental. A própria história do desenvolvimento do país comprova a contribuição dos jornalistas como agentes de transformação social e lutadores pela liberdade e pelos direitos dos cidadãos. Quando apresentou o Modelo curricular da Unesco para o ensino de jornalismo, Abdul Waheed Khan (UNESCO, 2010) comentou o desenvolvimento da democracia nos países emergentes:

Nos últimos anos, países em desenvolvimento e democracias emergentes registraram um rápido crescimento do número de meios de comunicação. Presenciou-se igualmente o reconhecimento do papel crucial do jornalismo na promoção da democracia, o que tem gerado uma demanda urgente por jornalistas formados com qualidade.

Por outro lado, as reflexões que trazem à tona questões sobre conceitos e relações do jornalismo são antigas e datam de 1690, ano em que foi defendida a primeira tese sobre jornalismo, De relationibus novellis, de Tobias Peucer, na Universidade de Leipzig, na Alemanha. A tese apresenta questões relacionadas à verdade e à credibilidade, além de tratar das narrativas e dos periódicos.

Manuel Carlos Chaparro (2014) afirma que muito se fala sobre interesse público no jornalismo, mas, antes de tudo, é preciso lembrar o seu conceito. Nesse sentido, o pesquisador recorre à ideia platônica do bem, que, para Platão, era princípio do ser e do conhecimento: “Assim como o Sol é a fonte da geração, do crescimento e da nutrição, o Bem é a causa da inteligibilidade de todas as coisas inteligíveis e também do ser e da essência” (PLATÃO, 1980, p. 178, apud CHAPARRO, 2014, p. 107). Ainda de acordo com o autor: 
Para Platão, a esfera do que é público está na cidade devidamente ordenada e nesse princípio de ordem e razão, em função da cidade justa e verdadeira, legou-nos o platonismo uma noção do que poderia ser chamado de interesse público. (CHAPARRO, 2014, p. 107-108).

O pesquisador também afirma que o jornalismo é o elo que, nos processos sociais, cria e mantém as mediações que viabilizam o direito à informação. Refere-se ao interesse, quando diz que é um atributo de definição do jornalismo. Para ele, "a palavra interesse é a que mais se repete nas definições do que seja jornalismo, simbolizando, na notícia, sua expressão de essência" (CHAPARRO, 2007, p. 146).

A afirmação do autor pode ser observada, por meio de analogias, desde textos antigos até os mais recentes que invocam a profissão. Em artigo publicado em 1986, Luiz Beltrão afirma que conceitos universalmente acatados da missão informativa e orientadora do jornalismo tratam de liberdade, de responsabilidade e de bem-estar social. Ferdinando Segismundo, em 1962, na época conselheiro e diretor da Associação Brasileira de Imprensa, coloca a objetividade e o apego à verdade como traços marcantes da profissão e diz que a sociedade tem o direito à informação correta e sem os controles, quer sejam dos anunciantes, quer sejam do governo. Para ele, as metas do jornalismo são informar, interpretar, dirigir e ensinar, tendo em vista, exclusivamente, as justas aspirações do povo e a indefectível soberania nacional (SEGISMUNDO, 1962).

É também nas menções sobre a prática jornalística e sobre a definição dos formatos e gêneros jornalísticos que o interesse público está presente. Ao definir o que é a reportagem, Beltrão (1969, p. 195) se refere ao "relato de uma ocorrência de interesse coletivo, testemunhada ou colhida na fonte por um jornalista e oferecida ao público, em forma especial e através de veículos jornalísticos". Sobre o repórter, o pesquisador diz que é aquele "que vai em busca dos dados para o levantamento, cobertura, narração e divulgação das ocorrências de interesse coletivo [...]" (BELTRÃO, 1969, p. 199). Já sobre o jornalismo de uma forma geral, o pesquisador diz que é visto como:

Processo de produção de mensagens culturais relativas a fatos, ideias e situações atuais, interpretados à luz do interesse coletivo e transmitidos periodicamente à sociedade, com o objetivo de difundir conhecimentos e orientar a opinião pública, no sentido de promover o bem comum. (BELTRÃO; QUIRINO, 1986, p. 156).

Ainda com o exemplo de Beltrão, quando escreve sobre reportagem, é oportuno registrar que, notadamente, todo o processo de sua construção deve se orientar pelo interesse público. Os elementos de sua produção, constituídos em pauta, pesquisa, coleta 
de informações, entrevistas, redação, edição e publicação, devem direcionar-se à contribuição que a veiculação poderá oferecer à sociedade. Além disso, o texto também necessita ser construído de forma que o público leitor tenha o melhor entendimento possível. Portanto, deve ser claro, preciso e efetivamente objetivo.

Já no âmbito das ciências jurídicas, com Mello (2013, p. 62), importante lembrar que interesse público é noção que ultrapassa a de interesse de um todo abstrato, para significar o "interesse resultante do conjunto dos interesses que os indivíduos pessoalmente têm quando considerados em sua qualidade de membros da Sociedade e pelo simples fato de o serem", alcançando os que a integram no presente e os que a integrarão no futuro.

Certo, também, que a informação é um bem de interesse público. Para nós, já numa necessária intersecção entre jornalismo e direito, interesse público é uma categoria do pensamento, de conteúdo plurissignificativo, mas determinável no caso concreto, que caracteriza o direito - e legitima seu exercício - da coletividade, enquanto conjunto de individualidades, de acessar informações dotadas de veracidade, ou opiniões qualificadas que ostentem utilidade social, política, econômica, cultural, sanitária, ambiental etc., autorizando e até mesmo justificando, no limite do necessário, a relativização da proteção conferida aos direitos individuais à privacidade, à intimidade, à honra e à imagem.

A informação difere do interesse do público, no qual se identifica a pretensão de um grupo identificado ou identificável de pessoas, de conhecer informações de seu interesse setorizado, e que atende quase sempre a curiosidades e anseios particulares, justamente por isso não oponível aos direitos individuais antes mencionados. No entanto, será juridicamente protegido, não ferindo indevidamente a intimidade, a privacidade, a honra e a imagem das pessoas, se nele se revelar a legítima pretensão de conhecer informações a respeito de fatos e de personalidades que, por sua projeção no meio social e por sua interação com grupos da sociedade, lhe despertem justo interesse. É o caso do interesse público em conhecer o estado de saúde de um artista famoso que se encontra hospitalizado, e que, tendo sido consumidor de sua arte, vê-se afetivamente ligado àquela personalidade, com interesse legítimo de acompanhar o desenrolar de seu quadro, desde que a notícia não adentre aspectos que, se divulgados, constranjam a pessoa de algum modo.

\section{As dificuldades e embaraços enfrentados pelo jornalismo na defesa dos direitos fundamentais}

O jornalismo tem a importante função de levar ao conhecimento da sociedade a existência dos direitos, contribuindo para seu reconhecimento e sua consolidação. Como mola deflagradora e propulsora, integra o processo de introjeção dos direitos. Cria, ao 
lado da educação formal (e até, não raro, com mais efetividade e agilidade), as condições para o desenvolvimento da cidadania, na acepção arendtiana, de direito a ter direitos. Não à toa, os inputs a que estamos sujeitos sobre direitos do consumidor, por exemplo, são cotidianamente fornecidos por reportagens jornalísticas, mais do que aprendemos nos bancos escolares. Direito que não é conhecido cai em desuso e definha. Precisa ser conhecido e divulgado, para ser usado e aplicado.

Mas não é só. O jornalismo tem o importante mérito de identificar e elevar a pretensão, o anseio e a necessidade que justificam o processo de gênese dos direitos. Para se ter uma ideia disso, observemos que a defesa das minorias, como pretensões juridicamente protegidas, nasce das agitações de alguns grupos sufocados por posições majoritárias e hegemônicas, que só ganham projeção quando divulgadas pelas redes sociais e pelas ações reiteradas e sistemáticas da imprensa, reproduzindo e também formando a opinião pública. Daí, quase sempre, nascem as iniciativas legislativas que, no futuro, produzirão e conformarão novos direitos. Entretanto, em continuidade com o que já foi dito antes, é relevante mencionar que seria ingenuidade se considerássemos que o jornalista sempre tem e terá plena liberdade para produzir e veicular exatamente o que é de interesse social. É notório que certas interferências de diversas ordens perpassam o fazer jornalístico, como hierarquias superiores, pressão do tempo, fatores políticos e econômicos, posição do veículo, negócios, competitividade e até mesmo a própria censura do judiciário por intermédio de decisões que impedem publicações.

Como bem lembra Traquina (2004, p. 31), "poucas profissões e poucos profissionais têm sido objeto de tanto escrutínio intensivo e tanta crítica escaldante quanto o Jornalismo e os jornalistas". Mas também é possível ousar, ao se afirmar que poucas profissões e poucos profissionais têm lutado veementemente pela liberdade, pela democracia e pela sociedade quanto os jornalistas e estudiosos da área.

De toda forma, é certo que essas interferências podem ameaçar o jornalismo e seus profissionais. As interpretações judiciais mostram-se, algumas vezes, problemáticas e geram algum nível de incerteza, de imprevisibilidade e de ansiedade negativa para a imprensa e para a sociedade enquanto consumidora da informação. Assim é que a Constituição Federal (BRASIL, 1988) assegura a liberdade de expressão, ao mesmo tempo que permite que, no exercício do direito de defesa, os cidadãos, cientes de reportagem a ser veiculada que lhes sejam desfavoráveis, recorram a uma decisão judicial, muitas de natureza liminar e acautelatória, impedindo a publicação e a circulação da informação. Nesses casos, abre-se espaço para uma discussão acirrada entre juízes e jornalistas, como bem apreendeu o ministro Luis Felipe Salomão, do Superior Tribunal de Justiça (2016, p. 384-385): 
Alguns magistrados entendem que as decisões judiciais proibindo a divulgação de informações se baseiam na Constituição Federal, que prestigia os direitos à privacidade e de imagem, em detrimento da notícia ou informação. Na verdade, para muitos juízes não há censura quando se preservam princípios assegurados no texto constitucional e ainda mais quando a decisão a ser impugnada com os recursos típicos do processo, situação muito diferente do censor do tempo da ditadura, que percorria as redações e, ao seu sabor e conveniência, ditava o que podia ou não ser publicado. Os jornalistas, ao contrário, defendem que sempre prevalece o direito de informação, vale dizer, "dever de prestar informação", mesmo quando contraposto a outros direitos fundamentais.

O ministro Carlos Ayres Britto manifestou-se a respeito (PENSADOR..., 2014,), no sentido de que "a própria Constituição já fez uma calibração entre dois blocos de liberdade e optou pelo bloco das liberdades de pensamento, de expressão e de informação”. Esse, aliás, foi o entendimento firmado pelo Supremo Tribula Federal, por ocasião do julgamento da ADPF no 130 (BRASIL, 2009), que reconheceu a não recepção da Lei de Imprensa pela Constituição Federal de 1988, em razão de sua incompatibilidade, do que decorreu o seu afastamento do ordenamento jurídico vigente. O ministro menciona que, no caso da imprensa, houve até um acréscimo, pois a Constituição referiu-se a "pensamento, expressão, informação e criação". Segundo Britto:

A Constituição, ao fazer sua opção pela liberdade de imprensa, pré-excluiu a ponderação, a calibração, a avaliação dos juízes. Ela mesma já estabeleceu uma primazia, uma precedência, que não cabe ao Poder Judiciário negar (PENSADOR..., 2014, p. 31).

É importante esclarecer que, no âmbito da doutrina do direito constitucional, não é unânime essa teoria dos sobredireitos, que coloca a priori e em situação de prevalência os direitos à informação, à expressão e ao pensamento, relativamente aos direitos à intimidade, à privacidade, à honra e à imagem. Há forte doutrina consolidada, com grande repercussão jurisprudencial (decisões produzidas pelos diversos órgãos do judiciário), no sentido de reconhecer que os direitos fundamentais têm igual hierarquia de valor (axiológica), e só no caso concreto é que se pode reconhecer a incidência mais marcante de um dos blocos de direitos. Há casos em que, necessariamente, prevalecerá o direito à informação; em outros, preponderará a proteção da intimidade, da privacidade, da honra e da imagem do indivíduo. Seja como for, tanto melhor será a solução judicial, quanto mais preservar todos os direitos em colisão, mesmo que uns preponderem sobre outros. A tal resultado se chega mediante o emprego do mecanismo lógico (hermenêutico) de cedência recíproca.

Como se resolverá, então, esse conflito, essa colisão entre direitos fundamentais? Especificamente no caso de choque entre o direito à informação, à expressão e ao 
pensamento, de um lado, e de intimidade, de privacidade, de honra e de imagem, de outro, o que determinará a prevalência do primeiro bloco será justamente a identificação de um interesse público. Onde e quando este estiver presente - o que ocorrerá quando a informação for de interesse da coletividade e, quase sempre, disser respeito a uma personalidade de projeção pública -, caberá ao judiciário, mais do que não impedir sua circulação, garantir que esse direito da sociedade, para além do direito individual do jornalista de informar, seja amplamente respeitado. No entanto, o magistrado deve assegurar que essa invasão à intimidade, à privacidade, à honra e à imagem, se dê nos exatos limites para que a informação de interesse público chegue ao conhecimento de todos. Eis aí uma invasão legítima, legal. O que exceder à estrita necessidade do interesse público não autoriza a vulneração da zona de proteção individual. Em outras palavras, o interesse público autoriza, legitima e limita o malferimento dos direitos à intimidade, à privacidade, à honra e à imagem. Daí a importância da categorização que empreendemos sobre o interesse público.

Judith Brito, então presidente da Associação Nacional de Jornais, (2011), comenta que, no geral, essas decisões de censura prévia judicial são feitas por políticos, que pretendem impedir a divulgação de informações consideradas por eles mentirosas ou ofensivas. A autora comenta que também ocorrem casos de figuras públicas, não necessariamente de autoridades, que, tendo ciência da publicação de alguma informação que lhes diz respeito, recorrem à Justiça para impedi-la, alegando questões como privacidade e proteção à imagem.

Há ocorrências mais graves, como o assassinato de jornalistas. De acordo com Emmanuel Colombié, diretor do departamento Américas da ONG Repórteres sem fronteiras (O JORNALISTA..., 2016), "esses repórteres tentam falar de assuntos que incomodam, trabalham de forma objetiva, mas se tornam alvos e o modo de extermínio é sempre por grupos encapuzados com armas de fogo".

De acordo com o relatório "Violência contra jornalistas e liberdade de imprensa no Brasil”, produzido em 2016 pela Federação Nacional dos Jornalistas (2016), nesse ano, foram registrados 161 casos de violência em que foram vitimados 222 jornalistas, pois, em algumas ocorrências, mais de um profissional foi agredido de alguma forma. O relatório da Fenaj ainda aponta como autores dessas violências, em primeiro lugar, as polícias, sendo que a maior parte dessas agressões ocorreu em manifestações de rua. Em segundo lugar, aparecem os próprios manifestantes. Em terceiro lugar, os políticos, incluindo seus parentes e assessores. O documento ainda aponta casos de ações judiciais, de censura por parte de empresários da comunicação, ocorrências de populares que agrediram jornalistas; casos de agressão por parte de trabalhadores/sindicalistas, de dirigentes/ torcedores esportivos e, por fim, de delegados, detentos/suspeitos, seguranças privados e 
profissionais liberais. Em quatorze casos de violência, os agressores não foram identificados. Dois jornalistas foram assassinados, sendo um em Minas Gerais e outro em Goiás.

Muitos casos vão além da falta de liberdade de imprensa, pois os profissionais sofrem agressões físicas e, como visto anteriormente, em 2016, dois jornalistas foram assassinados no país em decorrência da profissão.

\section{Considerações finais}

É interessante mencionar que, mesmo diante das interferências e tentativas de cerceamento da liberdade de imprensa, como foi exposto neste trabalho, o jornalismo deve manter-se fiel a seus valores e firme no propósito de servir à sociedade. O interesse público e a liberdade de imprensa, tratados em leis maiores, bem como em textos doutrinários, códigos de ética, convenções e outros dispositivos, são evocados pelo jornalista nas suas rotinas produtivas e simbolizam o próprio fazer jornalístico.

No cenário atual, em que o país enfrenta fortes intempéries nos planos político, econômico e social, é fundamental que o interesse público esteja efetivamente presente e governe a ação jornalística em todas as suas etapas, para além de qualquer compreensão enquanto fenômeno meramente utópico, inalcançável.

Por imperativo de imparcialidade e, consequentemente, utilidade da atividade comunicacional, não há espaço justificável para que se admita qualquer intimidação ao jornalista, inclusive diante das possíveis pressões que advêm daqueles que priorizam interesses particulares em detrimento do interesse público.

É dever do Estado de feição social e democrática, como se propõe a ser o brasileiro, por todas as suas funções de Poder - executiva, legislativa e judicial -, criar os meios adequados e eficientes para proteger a atividade jornalística diante das injunções derivadas da opulência peculiar do poder econômico e político, o que inclui o próprio Estado e seus agentes. Assim procedendo, os órgãos estatais criam as condições férteis ao exercício regular do direito à boa informação, de índole individual, mas essencialmente coletiva. Dele não se cobra apenas a conduta negativa de não impor embaraços à livre circulação de informações e opiniões, mas também posturas ativas, que vão desde criar condições para o acesso às informações de caráter público (incluindo as governamentais), como também assegurar a integridade física e a vida do jornalista, quando e em razão de seu exercício profissional, especialmente nas situações de risco, como manifestações populares. Deve também incentivar a formação do comunicador social e apoiar a livre iniciativa empreendedora que se dispõe a explorar o mercado de notícias. Criar marcos legais capazes de tutelar, mas sem sufocar as novas e já existentes 
plataformas, também é ação estatal necessária, assim como o cuidado do Judiciário em não impedir o trabalho jornalístico e, com isso, a formação da opinião pública, reconhecendo que a imprensa detém inquestionável e notável competência para conhecer e fiscalizar as coisas do Estado, de seus agentes e, enfim, que sejam de interesse do grupo social de que faz parte indissociável.

Já o jornalista, na maior medida possível, deve usar todas as formas de comunicação que tem à disposição, e que hoje são favorecidas pelo ambiente digital, explorando todos os seus recursos para fazer chegar à sociedade a notícia conforme o fato ocorrido, mesmo que tal ação contrarie aqueles que não se valem da transparência, mas, sim, da omissão ou manipulação da informação.

Também é dever do profissional atualizar-se, qualificar-se, emprestar ao produto do seu trabalho a excelência que a relevância da comunicação social tem no quadro das ciências da humanidade.

A liberdade de imprensa vivida no Brasil do século 21 é a indutora do interesse público, e o jornalista, cuja profissão é eminentemente social, deve orientar sua ação tendo em vista a sociedade e o bem comum. Assim, o interesse público não ficará confinado apenas às discussões, reflexões e aos documentos de ordenamento jurídico e ético. Ele deverá ser discutido sempre, assim como sempre deverá ser o norte do trabalho jornalístico.

\section{Referências}

BELTRÃO, L. A imprensa informativa: técnica da notícia e da reportagem no Jornal Diário. São Paulo: Folco Masucci, 1969.

BELTRÃO, L.; QUIRINO, N. O. Subsídios para uma teoria da comunicação de massa. 3. ed. São Paulo: Summus, 1986.

BRASIL. Constituição da República Federativa do Brasil de 1988. Diário Oficial da União, Brasília, DF, 5 out. 1988. Disponível em: <http://bit.ly/2fJH6OV>. Acesso em: 23 dez. 2016.

Supremo Tribunal Federal. Arguição de descumprimento de preceito fundamental $n^{\circ}$ 130-7-DF . Arguente: Partido Democrático Trabalhista. Arguidos: Presidente da República e Congresso Nacional. Interessada: Associação Brasileira de Imprensa. Relator: Min. Carlos Ayres Britto. Brasília, DF: STF, 30 abr. 2009. Disponível em: <http://bit.ly/1wu9hn1>. Acesso em: 23 jan. 2017.

BRITO, J. Indivíduo × sociedade. Estadão (on-line), São Paulo, 19 nov. 2011. Disponível em: < http://bit. ly/2oQYYYe>. Acesso em: 10 dez. 2012.

CHAPARRO, M. C. Pragmática do jornalismo: buscas práticas para uma teoria da ação jornalística. São Paulo: Summus, 2007.

Jornalismo: linguagem dos conflitos. São Paulo: Editora do Autor, 2014. 
FEDERAÇÃO NACIONAL DOS JORNALISTAS. Código de ética dos jornalistas brasileiros. Vitória: Fenaj, 2007. Disponível em: <http://bit.ly/2oQW7yP>. Acesso em: 23 dez. 2016. . Violência contra jornalistas e liberdade de imprensa no Brasil. Relatório 2016. Vitória: Fenaj, 2017. Disponível em: <http://bit.ly/2jQAlfg>. Acesso em: 2 maio 2017.

FERREIRA, M. A. A. Liberdade de imprensa: Líbero Badaró. Ribeirão Preto: Migalhas, 2011.

HOHFELDT, A. (Org.). Jornalismo cultural: temas de comunicação. Luiz Beltrão. São Paulo: Intercom, 2012. v. 2.

MELLO, C. A. B. Curso de direito administrativo. 30. ed. São Paulo: Malheiros, 2013.

O JORNALISTA se tornou alvo deliberado, diz Repórteres sem Fronteiras. Rádio França Internacional (RFI), Rio de Janeiro, 21 dez. 2016. Disponível em: <http://bit.ly/2p8Q6Ql>. Acesso em: 12 dez. 2016.

ONU - ORGANIZAÇÃO DAS NAÇÕES UNIDAS. Declaração universal dos direitos humanos de 1948. Paris: ONU, 1948. Disponível em: <http://bit.ly/1CVqinH>. Acesso em: 23 dez. 2016.

PENSADOR das liberdades. Entrevista com o ministro Carlos Ayres Britto. Revista Imprensa, São Paulo, ano 27, n. 303, 2014.

PEUCER, T. De relationibus novellis. (Tese de Doutorado). Leipzig: Universidade de Leipzig, 1690.

UNESCO - ORGANIZAÇÃO DAS NAÇÕES UNIDAS PARA A EDUCAÇÃO, CIÊNCIA E CULTURA. Modelo curricular da Unesco para o ensino de jornalismo. Brasília, DF: Unesco, 2010. Disponível em: $<$ http://bit.ly/2qbVxN8>. Acesso em: 2 set. 2011.

SALOMÃO, L. F. Direito privado: teoria e prática. 3. ed. rev., atual. e ampl. São Paulo: Saraiva, 2016.

SEGISMUNDO, F. Imprensa brasileira: vultos e problemas. Rio de Janeiro: Alba, 1962.

TRAQUINA, N. Teorias do jornalismo: porque as notícias são como são. Florianópolis: Insular, 2004. Teorias do jornalismo: a tribo jornalística - uma comunidade interpretativa transnacional. 2. ed. Florianópolis: Insular, 2008. v. 2. 